\title{
PERSPECTIVAS PARA A EDUCAÇÃo FísiCa ESCOLAR
}

Go TANI*

Perspectivas para a educação física escolar. Esse é o tema extremamente complexo que a organização do Seminário estabeleceu para esta mesa redonda.

Falar de perspectivas $€$ falar do futuro, ou seja, de algo que ainda está para acontecer. Envolve, portanto, muitas incertezas e possibilidades de errar. Mas, se levarmos em consideração que o futuro permite um grau de liberdade muito grande para a escolha de nossas acões, a expectativa também aumenta e nos deixa cheio de esperanças (Tani, 1988a).

Pretendo, interpretando positivamente este significado do futuro, apresentar a minha visão do problema, baseando-me em três pontos que julgo essenciais à educação física escolar, quando ela é analisada em termos de perspectivas: a conquista da autenticidade, a mudança de paradigma em relação ao movimento humano e a definição da sua especificidade.

\section{A CONQUISTA DA AUTENTICIDADE}

E muito comum observar-se na educação física um esforço muito intenso dos profissionais da área para convencer as pessoas de que ela $e$ importante. Eu tenho buscado para mim mesmo uma explicação para este fato. Tenho feito perguntas e tentado a elas responder.

A primeira pergunta que me vem à mente é naturalmente a seguinte: Por que os profissionais da área insistem tanto em convencer as pessoas de que a educação física é importante?

Resposta: Fundamentalmente porque as pessoas não estão convencidas disso. importante?

Pergunta: Por que as pessoas não estão convencidas de que a educação física é algo

Resposta: Fundamentalmente porque elas não sabem o que significa educação física. Muitas a confundem com atividade física.

Pergunta: Por que as pessoas não sabem o que é educação física?

Resposta: Fundamentalmente porque as ações dos profissionais da área não foram capazes de sensibilizá-las e informá-las a respeito, através de suas ações. informá-las?

Pergunta: Por que os profissionais da educação física foram incapazes de sensibilizá-las e educação física.

Resposta: Fundamentalmente porque eles próprios não têm uma definição clara do que $\epsilon$

Pergunta: Por que os profissionais não têm uma definição clara do que seja educação física?

Resposta: Fundamentalmente porque o curso de preparação profissional não foi capaz de lhes transmitir esta identidade.

Pergunta: Por que o curso de preparação profissional não foi capaz de transmitir uma identidade clara da educação física?

*Escola de Educação Física da Universidade de São Paulo. 
claramente definida.

Resposta: Fundamentalmente porque a própria educação física não tem a sua identidade

Para se ter uma base da dimensão desta ambigüidade, basta atentar para as diferentes utilizações da palavra educação física. Ela pode indicar no mínimo quatro coisas distintas, embora relacionadas (FIGURA 1): disciplina curricular, profissão, preparação profissional e área de conhecimento (Tani, 1989) e esta utilização indiferenciada da palavra educação física tem inibido uma discussão mais profunda dos seus problemas.

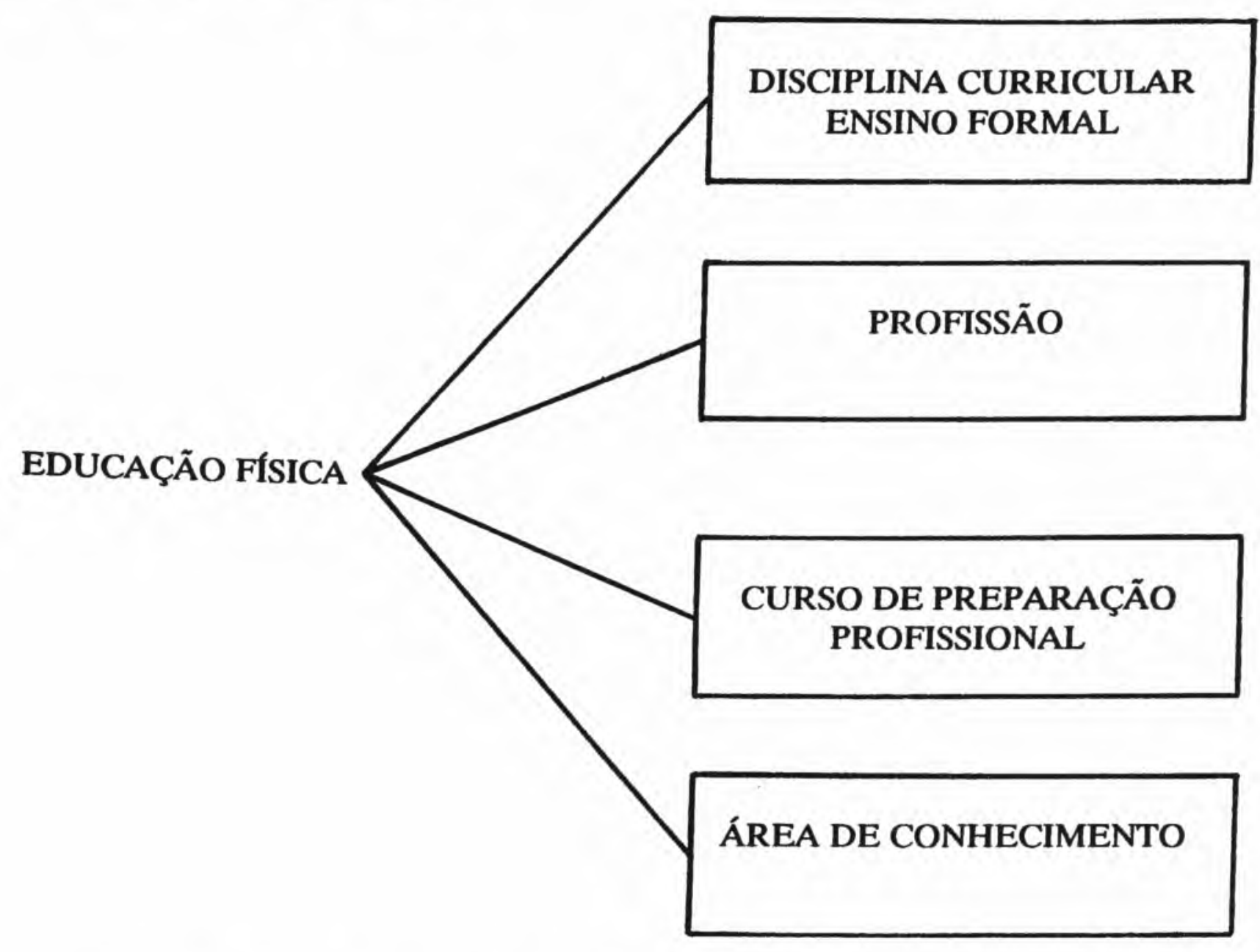

FIGURA 1- Os diferentes significados da palavra educação física.

Como profissão, os professores de educação física têm sido considerados, muitas vezes, simples executores com baixo reconhecimento profissional, marginalizados pelos próprios colegas professores de outras disciplinas curriculares. Agora, esta imagem que os professores de educação física possuem, não é fruto do mero acaso. Para compreendê-la melhor, basta verificar a preparação profissional a que eles foram submetidos.

As Escolas de Educação Física, em nome de uma formação eclética do professor, têm lançado ao mercado de trabalho profissionais de perfis indefinidos e desorientados em relação a sua prática profissional. Estes profissionais, ironicamente, disputam este "mercado de trabalho" tão enfatizado pelos dirigentes responsáveis pela estruturação dos currículos destas Escolas de Educação Física, com pessoas sem a devida habilitação profissional específica.

Esta ambigüidade na preparação profissional reflete nada mais nada menos que a ausência de uma identidade clara da educação física. Ao meu ver, esta ausência de identidade tem suas raízes no fato da educação física ter, historicamente, enfatizado o ensino, o aspecto profissionalizante, esquecendo-se de se estruturar enquanto uma área de conhecimento. 
Embora preocupar-se em contribuir para as pessoas seja fundamental sobre o ponto de vista da profissão, o não desenvolvimento de uma área de conhecimento através de pesquisas, coloca em cheque a propria autenticidade e porque não dizer a sobrevivência da profissão (Tani, 1989).

Uma verdadeira profissão, segundo Lawson (1979), é caracterizada por um corpo teórico codificado de conhecimento profissional sobre o qual julgamentos práticos estão baseados. Portanto, para uma profissão é imprescindível o desenvolvimento de um corpo de conhecimentos através de estudos e pesquisas e a sua utilização para melhorar a qualidade da prática profissional.

No contexto escolar, existe uma indefinição muito grande sobre o real papel da educação física e o conténdo por ela desenvolvido. Se comparado a outras disciplinas curriculares, na sua relação com as respectivas áreas do conhecimento, nota-se que a física existe independentemente do ensino da física. A química, a matemática, a biologia idem. E a educação física? Embora ela exista enquanto ensino qual seria a área de conhecimento correspondente e qual seria o seu conteŕdo (FIGURA 2)?

\begin{tabular}{|c|c|c|}
\hline EDUCAÇÃO & \multicolumn{2}{|c|}{ ÁREA DE CONHECIMENTO } \\
\hline ENSINO DA MATEMÁTICA & - & MATEMÁTICA \\
\hline ENSINO DA QUIMICA & - & QUIMICA \\
\hline ENSINO DA FÍSICA & - & FISICA \\
\hline ENSINO DA BIOLOGIA & - & BIOLOGIA \\
\hline ENSINO DA EDUCAÇÃO FIs & ICA - & $?$ \\
\hline
\end{tabular}

FIGURA 2- Disciplinas curriculares e as áreas de conhecimento correspondentes.

Em suma, o que gostaria de ressaltar, nesta oportunidade, é que se a educação física não se estruturar enquanto área de conhecimento, as ambigüidades da educação física escolar continuarão e será diffícil a conquista da autenticidade.

\section{MUDANÇA DE PARADIGMA EM RELAÇĀO AO MOVIMENTO HUMANO.}

a)O ser humano como sistema aberto e o movimento.

O ser humano é um sistema aberto, ou seja, um sistema que interage com o meio ambiente através da troca de matéria/energia e informação e que está em constante busca de estados mais complexos de organização. Um sistema em não equilíbrio que muda, evolui e evita o aumento de entropia previsto pela 2a. lei da termodinâmica. Um sistema que projeta novos objetivos assim que o objetivo inicial é alcançado, caracterizando um comportamento teleológico dentro de um desenvolvimento hierárquico.

O movimento, em sistemas abertos, além de ser o instrumento pelo qual eles interagem com o meio ambiente, $\epsilon$ também um elemento que contribui para uma crescente ordem no sistema (Tani, 1988b). 
Para que ocorra o movimento humano dois elementos são essenciais: energia e informação; e a relação que se estabelece entre estes dois elementos é que o primeiro é controlado pelo segundo, pois a energia só se torna eficaz quando é controlada. Ouanto aos mecanismos da performance humana, o sistema muscular é aquele diretamente relacionado com a energia è o sistema nervoso central aquele relacionado com a informação. E fundámental a compreensão de que quando o ser humano executa movimentos, o objetivo não é o gasto de energia, mas sim através do dispêndio energético adquirir informações para organizá-los e controlá-los com o intuito de alcançar objetivos predeterminados.

$E$ através do movimento que o ser humano faz a verificação experimental (testagem) do conhecimento (plano de ação) mentalmente elaborado. Em outras palarras, o movimento coloca em prática o conhecimento mentalmente elaborado e através da comparação do resultado e do objetivo a ser alcançado torna possível a correção da eventual discrepância. Com isto, aumenta a organização e contribui para uma crescente ordem no sistema. Os conhecimentos não testados atraves do movimento são inconsistentes, pois carecem de verificação. $O$ reconhecimento do mundo ao redor seria impossível sem o movimento.

b) $O$ princípio da eqüifinalidade no movimento humano.

Uma das características dos sistemas abertos é que eles podem alcançar um mesmo estado final, a mesma meta, partindo de diferentes condiçôes iniciais e por diferentes trajetos (Bertalanffy, 1977).

O ser humano é capaz de alcançar uma mesma meta ou realizar uma mesma ação via diferentes movimentos. Por exemplo, imagine um individuo escrevendo o seu próprio nome primeiro com um lápis mantido na sua mão preferida. Imagine agora escrevendo com a mão não preferida e depois com o lápis preso entre os dedos dos pés, entre os dentes e assim por diante. Embora em cada um destes movimentos haja uma diferença de habilidade, é inegável que um mesmo objetivo esteja sendo alcançado utilizando-se diferentes grupos musculares, ou seja, através de diferentes movimentos.

Esta característica de eqüifinalidade presente no movimento humano suscita a seguinte pergunta: se o ser humano é capaz. de alcançar uma meta ou ação via diferentes movimentos, por que a educação física insiste tanto em tentar ensinar para os alunos, desde o início da aprendizagem, uma determinada técnica de movimento, se pela própria definição, técnica é o (um) meio mais eficiente para alcançar determinado objetivo?

Embora a repetição de uma determinada técnica possa conduzir mais rapidamente à padronização do movimento, tornando a aprendizagem aparentemente mais eficiente, esta padronização corresponde também a uma perda proporcional de flexibilidade nas respostas. $\mathrm{Em}$ outras palavras, pode levar à formação de movimentos de características fixas e estereotipadas, prejudicando a adaptabilidade que é fundamental em sistemas abertos.

Em educação física, muitos professores fazem com que os alunos repitam simplesmente uma técnica de movimento selecionada por eles, tornando o processo de aprendizagem uma experiência monótona que se reduz a repetições pura e simples de movimentos com o propósito de atender as especificaçōes da técnica.

É preciso encorajar os alunos a variar suas açōes até que encontrem um padrão de movimento correspondente a uma técnica ou semelhante a ela. Afinal, a eqüifinalidade dos sistemas abertos permite ao ser humano alcançar uma mesma meta via diferentes movimentos.

Neste sentido é fundamental uma mudança de paradigma no que se refere a prática. Prática em educação física não significa uma mera repetição de movimentos para solucionar problemas motores, mas sim a repetição do processo de solucioná-los (Bernstcin, 1967), em que cada tentativa envolve um processo consciente de elaboração, execução, avaliação e modificação de açōes motoras. Em outras palavras, prática é um tipo particular de repetição sem repetição, visto que se essa condição for ignorada, ela se tornará meramente uma repetição mecânica de rotina.

E preciso mudar a educação física em que o professor entende o aluno como um sistema fechado, onde ele define o problema, a maneira de solucioná-lo, estabelece o número de tentativas necessárias para solucioná-lo, não permite a mudança de objetivo, do valor alvo e assim por diante. 
c) A organização hierárquica do movimento humano.

Dentro da visão do ser humano como um sistema aberto, é importante considerar a dinâmica de mudança que o sistema apresenta ao longo do tempo que é de natureza hierárquica. Em relação ao movimento humano, especificamente, o desenvolvimento hierárquico de habilidades motoras pressupõe dois processos fundamentais, quais sejam: o aumento da diversificação do comportamento (horizontal) e o aumento da complexidade do comportamento (vertical). Entende-se por aumento da diversificação do comportamento, o aumento na quantidade de elementos do comportamento, e por aumento da complexidade, o aumento da interação entre os elementos do comportamento (Choshi, 1983).

Se a educação física escolar tem como princípio possibilitar a todas as crianças explorar ao máximo suas potencialidades motoras, respeitadas as suas características individuais, os seus programas devem proporcionar oportunidades que possibilitem aos alunos alcançar estados cada vez mais complexos de organização, através do aumento de diversificação e de complcxidade do comportamento, caracterizando um desenvolvimento hierárquico de habilidades motoras cuja extremidade continua sempre aberta.

\section{A DEFINIÇÅO DA ESPECIFICIDADE}

Tem sido um lugar comum, ainda nos dias de hoje, uma visão otimista ingênua da educação física que a superestima, atribuindo-lhe poderes que ela não tem e nem poderia ter, bem ao estilo do "romantismo pedagógico" movido por slogans e discursos inflamados do tipo "educação física é saúde", "educação física é cultura", "educação física é felicidade", enfím, educação física é tudo. Esta visão, ao meu ver, tem inibido a devida caracterização da educação física e dificultado, conseqüentemente, a identificação das reais dimensões de suas possibilidades e limitações.

Paralelamente, há uma outra corrente que chamaria de "educação física social" a qual, em vez de preocupar-se com a educação física em si, transfere sistematicamente a discussão dos seus problemas para níveis mais abstratos e "macroscópicos" onde, com freqüência, discursos genéricos e demagógicos de cunho idelógico e político-partidário, sem propostas reais de programas de educação física, têm contribuído para tornar ainda mais indefinido o que já está suficientemente ambíguo.

Neste contexto, é muito comum, quando alguém fala em especificidade da educação física ser rotulado de reducionista ou simplista, particularmente por aqueles portadores de discursos genéricos e abstratos referidos anteriormente, que preferem sempre falar de totalidade, embora não esclareçam o que entendem por essa totalidade. Em educação física, falar de especificidade, necessita, estranhamente, de coragem e ousadia.

Fala-se muito que "educação física é educação". Será que esta colocação está clara? O que significa isto mais exatamente? Atuando de que forma a educação física estará sendo ou não educacional? Não será este um dos muitos "chavões" que a educação física utiliza para justificar corporativamente a sua existência. sem analisar profundamente o seu significado?

Freqüentemente, observamos na educação física, o estabelecimento de vários objetivos gerais e outros tantos específicos. Será que a educação física tem condições de assumir que todos estes objetivos serão realmente alcançados? Será que não estamos estabclecendo "levianamente" os seus objetivos? Será que não estamos brincando de educação? Todas as profissões respeitadas e reconhecidas têm seus objetivos delimitados, bem definidos e são "cobradas" pela sociedade em função destes objetivos. Como ficará a educação física se um dia a sociedade exigir dela o cumprimento de todos os objetivos que ela estabelece?

A educação preconiza o desenvolvimento do ser humano, da criança, na sua totalidade. De que forma a educação física, como parte integrante dessa educação contribui para isto?

Definir a função da parte (educação física) no todo (educação) é uma tarefa de identificação da especificidade e não de discussão de generalidades. Neste sentido, $€$ importante ressaltar a pertinência da abordagem sistêmica em que em vez de entender o todo a partir das partes procura-se a partir do todo 

identificar a função das partes e a relação que as partes mantêm entre si para que o objetivo do todo seja
alcançado.

Qual seria então a função da educação física no desenvolvimento da criança? Qual seria a sua especificidade no contexto educacional? $O$ que cabe a ela desenvolver, e de que maneira?

Para tentar responder a estas perguntas é preciso, em primeiro lugar, reconhecer que $\epsilon$ impossível falar do papel da educação física sem definir o movimento humano como seu objeto de estudo e aplicação. Oualquer que seja a abordagem ou a ênfase que se atribui aos programas de educação física (por exemplo, educação física humanista, desenvolvimentista, holista, individualizada, etc), o seu foco central é o movimento humano.

Como poderia o movimento ser trabalhado na educação física de forma que ele favoreça o desenvolvimento da criança?

A educação física escolar, particularmente na pré-escola e nas quatro primeiras séries do ensino de 10. grau defronta-se com dois temas fundamentais de trabalho: a aprendizagem do movimento e a aprendizagem através do movimento. Parece-nos que na educação física atualmente desenvolvida, a ênfase está sendo colocada na aprendizagem através do movimento, onde a criança utiliza o movimento como meio para aprender sobre aspectos não necessariamente inerentes ao proprio movimento. Halverson (1971) caracteriza a aprendizagem através do movimento como aquela que implica no uso do movimento como meio para alcançar um fim, mas que o fim não é necessariamente uma melhora na capacidade de se mover efetivamente. $O$ movimento é um meio para o aluno aprender sobre si mesmo, sobre o meio ambiente e sobre o mundo.

Todavia, se levarmos em consideração a importância do movimento no desenvolvimento do ser humano, as evidências dos estudos sobre desenvolvimento motor que nos permitem identificar o real significado do movimento dentro do ciclo de vida da pessoas e também o fato de que o movimento para ser usado efetivamente como meio para um fim, precisa ser primeiramente desenvolvido visto que ele não progride a um nível ótimo sem um trabalho adequado, acredita-se que a prioridade na educação física, particularmente para crianças nesta faixa escolar, é a aprendizagem do movimento onde elas aprendem a se mover, beneficiando-se dos aspectos inerentes ao próprio movimento. Segundo Halverson (1971), aprender a mover-se envolve contínuo desenvolvimento da capacidade de usar o corpo efetivamente e graciosamente com crescente evidência de controle e qualidade no movimento. Envolve o desenvolvimento da capacidade de mover-se numa variedade de maneiras, em situaçñes esperadas e inesperadas e nas tarefas crescentemente complexas. Isto requer mais que uma resposta mecânica automática. Aprender a mover-se envolve atividades como tentar, praticar, pensar, tomar decisōes, avaliar, ousar e persistir (p.18).

Na realidade, numa experiência de movimento, é difícil separar a aprendizagem do movimento e aprendizagem através do movimento, visto que estes dois aspectos estão intimamente relacionados e não podem ser mutuamente exclusivos. Porém, acredita-se que como conseqüência da aprendizagem do movimento onde um trabalho adequado com habilidades básicas é desenvolvido, outros aspectos não inerentes ao próprio movimento como a socialização e o desenvolvimento afetivo-emocional também são alcançados. Em outras palavras, os benefícios da aprendizagem através do movimento serão alcançados como conseqüência de um trabalho adequado com a aprendizagem do movimento. Sabe-se, por outro lado, que o inverso não necessariamente ocorre, ou seja, a aprendizagem através do movimento contribuir para a aprendizagem do movimento. Entende-se por trabalho adequado, aquele que sob o ponto de vista metodológico atende às expectativas e necessidades das crianças, proporcionando oportunidade para que elas possam desenvolver todas as suas potencialidades de movimento, levando-se em consideração suas características e limitações (Tani, 1987).

A aprendizagem através do movimento não é um privilégio exclusivo da educação física. Qualquer outra disciplina curricular pode promovê-la. Não há nenhum impedimento para que a disciplina de português, por exemplo, promova a alfabetização utilizando o movimento como meio, muito pelo contrário. $O$ mesmo pode ser dito em relação à matemática, à física e assim por diante. Não é preciso lembrar que não há nenhuma lei determinando que estas disciplinas curriculares sejam desenvolvidas unicamente nas salas de aula, com os alunos devidamente sentados, usando exclusivamente 

o "intelecto" mesmo que a visão dicotomizada do ser humano seja ainda muito comum no processo
educacional.

Em função destas colocações, acredito que a especificidade da educação física escolar, particularmente nas séries iniciais do ensino de 1o. grau é promover a aprendizagem do movimento (Tani, 1987; Tani, Manoel, Kokubun \& Proença, 1988).

Entretanto, existe uma outra dimensão da aprendizagem relacionada ao movimento, além da aprendizagem do e através do movimento, que $e$ a aprendizagem sobre o movimento (FIGURA 3), ou seja, a aquisição do corpo de conhecimentos racionais e objetivos sobre o movimento humano.

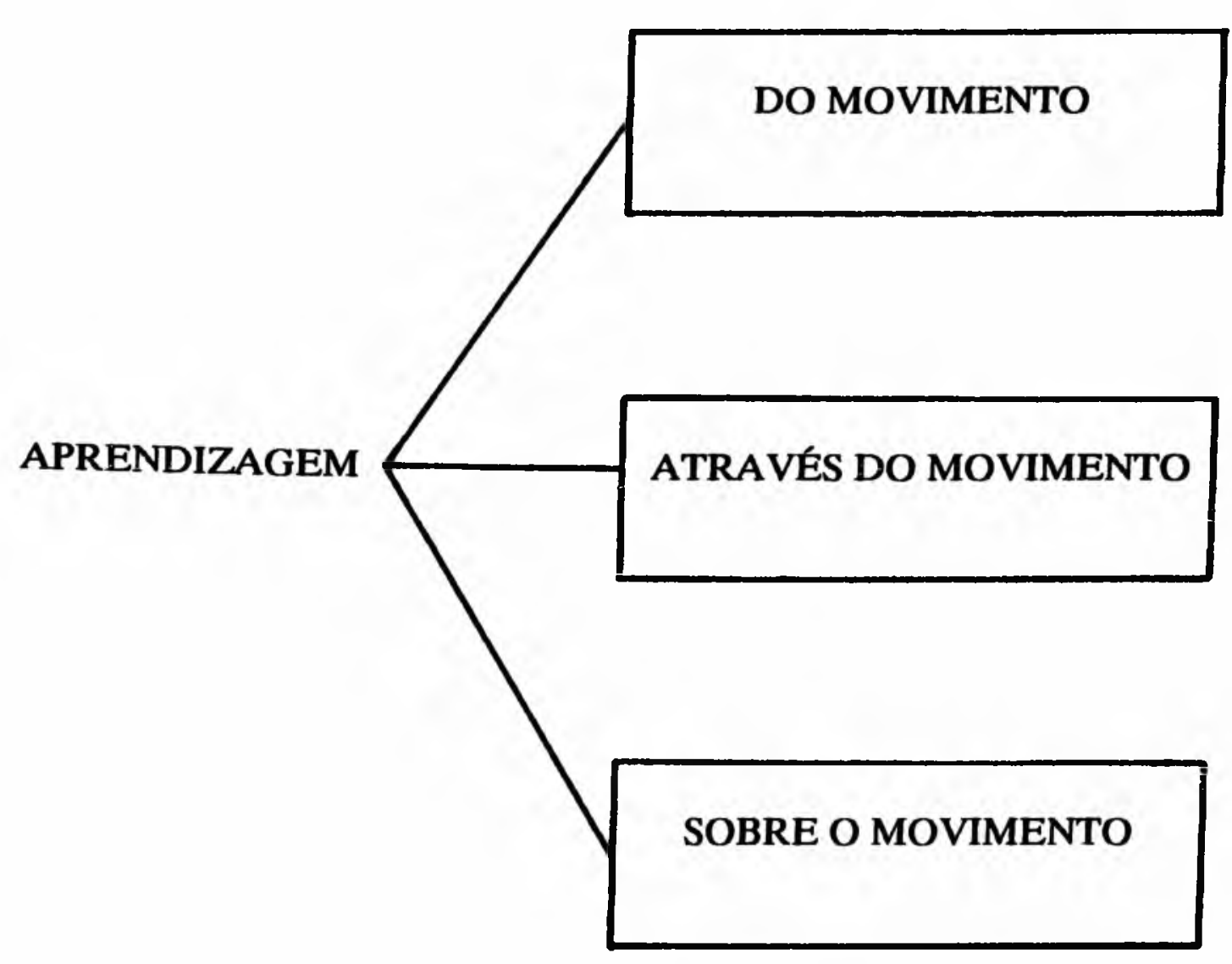

FIGURA 3- Diferentes tipos de aprendizagem relacionada ao movimento humano.

Estes conhecimentos, produzidos por estudos abrangentes e profundos que vão do nível de análise bioquímico até o sócio-cultural, são importantes não apenas pelo seu valor cultural e informacional, mas também pelo seu valor utilitário e instrumental, para serem aplicados às situações práticas ou para servirem de orientação na compreensão dos mecanismos e significados daquilo que será praticado pelo indivíduo ao longo de sua vida: o movimento.

Através da aprendizagem sobre o movimento, a educação física escolar transmitiria, em forma de aulas teóricas, conceitos, processos e procedimentos para caracterizar o movimento como um importante aspecto biológico, psico-social e cultural da vida do ser humano.

Considerando, portanto, o valor inerente da transmissão desses conhecimentos e o fato de que tempo, espaço e material específico são condições nem sempre atendidas numa aula de educação física nas escolas, o que impede muitas vezes a prática em si de movimentos, e consequentemente o alcance dos objetivos, a aprendizagem sobre o movimento torna-se particularmente para o ensino de 2o. grau, um aspecto que merece ser melhor estudado para ser efetivamente implantado. 
Acredito que a aprendizagem sobre o movimento, harmonicamente integrado à aprendizagem do movimento e portanto com implicações também sobre a aprendizagem através do movimento, possa constituir-se no futuro bem próximo, uma solução inteligente para a educação física escolar e isto reforça aquela minha preocupação manifestada no início desta apresentação de que é crucial a estruturação da educação física enquanto área de conhecimento.

E possível estruturar a educação física escolar de forma que os conhecimentos sobre aprendizagem motora, fisiologia do exercício, biomecânica, bioquímica do exercício, desenvolvimento motor, antropologia do esporte, sociologia do esporte e assim por diante, sejam selecionados à luz de critérios educacionalmente orientados para constituir cursos coerentes de estudo e aplicação do movimento humano, devidamente adequados às expectativas e necessidades dos alunos. Dentro deste contexto, se para a educação física nas séries iniciais do ensino de 1o. grau a aprendizagem do movimento é fundamental, a aprendizagem sobre o movimento poderá vir a ser prioritário no ensino de 20 . grau, em relação a outros tipos de aprendizagem relacionados ao movimento.

Finalmente, é importante ressaltar que as expressões "aprendizagem do movimento" e "aprendizagem através do movimento" têm sido, com freqüência, erroneamente interpretadas e confundidas com as expressões "educação do movimento" e "educação pelo movimento".

A aprendizagem é considerada a preocupação central do processo educacional, independente das especificidades de cada componente curricular. Em educação física, pelo fato do movimento humano constituir-se o objeto básico de estudo e aplicação, a abordagem desenvolvimentista assume como preocupação central da educação física escolar a aprendizagem do movimento.

Para analisar a adequação da utilização de expressões acima mencionadas é pertinente considerar, inicialmente, que a abordagem desenvolvimentista é um sub-sistema de um sistema chamado educação física escolar e a educação física escolar, por sua vez, é um sub-sistema de um sistema denominado educação.

Dentro desta organização hierárquica, as expressões "educação do movimento" e "educação pelo movimento" deveriam ser utilizadas quando se aborda a relação entre educação (sistema) e educação física escolar (sub-sistema). Além disso, é relevante observar que dentro de uma visão sistêmica, a estrutura hierárquica de objetivos pressupõe que, embora o sub-sistema tenha seu próprio objetivo, na sua relação com o sistema, ele se torna meio para que o sistema alcance o seu objetivo, isto É, a rếação objetivo-meio numa estrutura hierárquica de objetivos, necessita ser relativizada. Neste sentido, se a educação física escolar utiliza o movimento humano como seu objeto de estudo e aplicação, na sua relação com a educação (sistema), é pertinente e compreensível a utilização da expressão "educação pelo movimento". Por outro lado, a expressão "educação do movimento" tem toda uma matriz teórica que tem origem nos estudos de Laban (1978), cuja análise foge ao escopo deste trabalho.

Importante lembrar, para concluir, que perceber o nível e a extensão de análise que estão sendo adotados num determinado estudo ou discussão é fundamental para que a comunicação acadêmica efetivamente aconteça. Muitas discussões calorosas que ocorrem na nossa área não chegam a conclusões em função das dificuldades que os protagonistas destas discussões têm de perceber o nível (vertical) e a extensão (horizontal) de análise. Em outras palavras, as discussões acontecem fora de contexto, como por exemplo, aquela em que se discute que o movimento não se educa mas sim a pessoa, ou ainda, aquela em que se discute que a aprendizagem do movimento desconsidera outros aspectos do comportamento humano. Infelizmente, estas discussões fora de contexto, independente do mérito que cada assunto possa ter, não contribuem para uma melhor compreensão da educação física escolar. 


\section{REFERENCLAS BIBLIOGRÁFICAS}

BERNSTEIN, N. The co-ordination and regulation of movements. Oxford, Pergamon, 1967.

BERTALANFFY, L. von Teoria geral dos sistemas. Petropolis, Vozes. 1977.

CHOSHI, $\mathrm{K}$. Introduction to the study of pre-school that leads one to like movement. Taikukakyoiku, n.31, p.25-8, 1983. (em japonês).

HALVERSON, L.E. The young child...the significance of motor development. In: ENGSTROM, ed. The significance of the young child's motor development. Washington, D.C., National Association for the Education of Young Children, 1971.

LABAN, R. Domínio do movimento. São Paulo, Summus, 1978.

LAWSON, H.A. Paths toward professionalization. Quest, n.31, p.231-43, 1979.

TANI, G. Educação física e esportes na universidade: uma abordagem desenvolvimentista. In: PASSOS, S.C.E., org. Educação física e esportes na universidade. Brasília, SEED-MEC/UnB, 1988a. p.25-34.

TANI, G. Educação fisica na pré-escola e nas quatro primeiras séries do ensino de primeiro grau: uma abordagem de desenvolvimento. I. Kinesis, n.3, p.19-41, 1987.

TANI, G. Perspectivas da educação física como disciplina acadêmica. In: SIMPÓSIO PAULISTA DE EDUCAÇÃO FÍSICA, 2., Rio Claro, 1989. Anais. Rio Claro, UNESP, 1989.

TANI, G. Pesquisa e pós-graduação em educaçāo física. In: PASSOS, S.C.E., org. Educaçáo nísica e esportes na universidade. Brasília, SEED-MEC/UnB, 1988b. p.381-94.

TANI, G. et alii. Educaçāo fisica escolar: fundamentos de uma abordagem desenvolvimentista. São Paulo, EPU/EDUSP, 1988. 